\title{
Research on the Training Plan of Excellent Police Personnel in Cyberspace Security under the Intelligent Policing Mode
}

\author{
${ }^{1}$ China People's Police University, Langfang, China \\ ${ }^{2}$ China People's Police University, Langfang, China \\ ${ }^{3}$ China People's Police University, Langfang, China \\ a54227973@qq.com \\ b787923595@qq.com \\ c51544386@qq.com
}

Ma Jinqiang ${ }^{1, a}$, Tian Junjing ${ }^{2, b}$, Zhang Bo ${ }^{3, c}$

\begin{abstract}
Under the background of New Engineering and Excellence 2.0 project, the public security higher education should focus on the new demand of outstanding police personnel of cyberspace security in the new era, and train cyberspace security personnel with absolute loyalty, good legal thinking and practical ability, innovate the professional curriculum system and teaching methods in the teaching reform for the specialty of cyberspace security and law enforcement, pay attention to practical teaching, and make the training plan which is suitable for the growth of outstanding police personnel in the field of network security, and create a new pattern of training outstanding police personnel in public security colleges.
\end{abstract}

Keywords: Outstanding talents, police affairs, cyberspace security, training plan

\section{智慧警务模式下网络安全卓越警务人才培养计划研究 马金强 ${ }^{1, \mathrm{a}}$, 田俊静 ${ }^{2, \mathrm{~b}}$, 张波 $^{3, \mathrm{c}}$}

\author{
${ }^{1}$ 中国人民警察大学，廊坊，河北，中国 \\ 2 中国人民警察大学，廊坊，河北，中国 \\ ${ }^{3}$ 中国人民警察大学，廊坊，河北，中国 \\ a 54227973@qq.com \\ b787923595@qq.com \\ c51544386@qq.com
}

\section{摘要}

新工科与卓越 2.0 计划背景下，公安高等教育应围绕新时期公安工作对网络安全卓越警务人才的新 需求, 以培养绝对忠诚、具备良好法治思维与实战能力的网络安全保卫人才为核心, 在网络安全与 执法专业教学改革中创新专业课程体系、教学方法、评价机制, 注重实战技能训练, 建立一套适合 网络安全卓越警务人才成长的培养计划, 开创公安院校卓越警务人才培养新格局。

关键词: 卓越, 警务, 网络安全, 培养计划

\section{1. 前言}

2017 年 2 月以来, 教育部积极推进新工科建设, 先后形成了 “复旦共识” 、“天大行动” 和 “北京指
南” ${ }^{[1]}$ 。2018 年 9 月 17 日, 教育部印发《关于加快 建设高水平本科教育 全面提高人才培养能力的意见》 (简称 “新时代高教 40 条”) 等文件, 决定实施 “六 卓越一拔尖” 计划 $2.0^{[2]}$ 。与此同时, 以大数据、人 
工智能等信息技术为支撑的智慧警务新理念和新模 式, 正推动着新一轮警务改革与发展。当前, 国际局 势复杂多变, 中美之间摩擦不断, 我国安全形势面临 新的形势、新的变化, 特别是在网络空间领域, 敌对 势力不断通过网络对我国关键信息基础设施进行渗 透攻击, 信息泄露事件不断曝出。另一方面, 在公共 安全领域, 网络犯罪成为违法犯罪领域的第一大犯罪 类型。警察是国家重要的执法、护法力量，警务人才 是维护国家安全的重要法治人才 ${ }^{[3]}$ 。因此, 在公安高 等院校专业教育中，培养一批绝对忠诚可靠、掌握网 络安全新技术新理念、具有较强网络安全管理思维与 实战能力的卓越警务人才成为当务之急。

\section{2. 新工科与卓越人才培养}

新工科教育作为一种新型的高水平人才培养体 系, 是新的历史条件下教育主动适应新技术、新产业、 新经济发展而提出来的新理念。“新工科”、“卓越”计 划 2.0 在建设目标上紧紧围绕国家发展需要, 主动适 应新一轮科技革命和产业变革提出的新要求, 更好地 服务社会经济发展; 在发展路径上注重交叉融合, 破 除专业分割壁垒, 促进学科融合发展, 加强学科专业 间互动互促, 为传统学科专业建设注入强大动力和发 展后劲; 在人才培养上更加突出复合性、应用性和创 新性特征, 能较好应对未来挑战, 所培养的人才更善 于解决问题矛盾。“新工科”、“卓越” 计划 2.0 对 新时代的中国高等教育提出了新的期望。

公安教育作为高等教育与公安工作的重要组成, 各类警察院校警务人才培养模式不断发展、变革, 人 才培养体系不断优化, 人才培养质量不断提升。但随 着社会发展, 互联网技术的深度应用, 网络已经紧密 的与社会形成一体, 成为社会生态的重要环节。打击 网络犯罪、维护网络安全、保障网络平稳运行是公安 工作的重要职责。网络空间领域的保卫是智力与能力 的比拼, 是顶尖人才之间的比拼, 网络安全保卫现实 需求和警务模式的转变, 使公安工作需要大量优秀网 络安全警察。因此, 秉承新工科教育新理念, 公安院 校探索适合公安警务需求的卓越警务人才培养解决 方案具有重要意义。

\section{3. 网络安全卓越警务人才内涵}

\section{1. 公安工作新需求}

新时代下, 公安工作面临新形势, 建设更高水平 的平安中国建设全面展开, 在全面推进依法治国背景 下, 新技术新应用新思维深入影响着公安工作转型发 展。如何加强社会公安安全治理成为公安工作的重大 课题, 其中, 如何应对日益增加的网络犯罪案件, 如 何从法治、技术管控等方面全面加强网络虚拟社会治 理是重要内容。科学技术是第一生产力, 人才培养又 是科学技术发展的核心。大量优秀的警务人才是推进 公安工作的重要保障。自 2009 年网络安全与执法专
业开设以来，10 多所公安高等院校均设置了该专业， 招生规模不断扩大, 这些反应出公安工作对网络安全 人才的强烈需求。然而, 信息技术的迭代十分迅速, 新技术新应用层出不穷, 网络空间安全领域的竞争异 常激烈，网络空间的竞争很大程度就是人才的竞争， 人才的培养依托培养模式的构建, 新形势下的公安工 作对网络安全人才的培养提出了新要求。

\section{2. 网络安全卓越警务人才培养核心要义}

首先, 明确公安工作对网络安全卓越警务人才的 要求。网络警察是一个公安技术类警种, 履行维护国 家网络空间安全和网络社会稳定的职责, 依托计算机、 网络、通信、电子等基础理论, 针对网络空间目标开 展网络攻防、网络侦控、网络管控、电子数据勘查取 证, 防范、打击、控制、处置网络违法犯罪和突发案件 等专门工作 ${ }^{[4]}$ 。因此, 需要培养具备对互联网各类违 法犯罪活动进行 “打、防、管、控” 能力和服务正常 网络运行的网络警察。其次, 明确网络安全卓越警务 人才培养指导理念。卓越警务人才是卓越人才培养的 组成部分, 是面向公安工作的。而网络安全保卫是公 安工作的一部分, 网络安全卓越警务人才是掌握先进 网络技术的部分优秀人才。因此，网络安全卓越警务 人才培养有别于普通的警务人才培养模式, 是一种特 殊的、精英性质的人才培养。

综上可以得出, 安院校培养的卓越警务人才是一 种优中选优、采用非常规公安教育方式培养的卓越拔 尖人才。卓越警务人才表现为政治品质、业务能力和 创新发展三方面。具体到网络安全与执法专业上, 该 专业具有明显的工程技术属性, 也是一个新兴、快速 发展的公安技术专业, 在“新工科”、“卓越”计划 2.0 精神指引下, 开展人才培养计划改革具有良好的可行 性。在网络安全与执法专业开展卓越警务人才培养计 划就是要制定创新形式的人才选拔方式、独特教学模 式、多样化评价方法的人才培养方案。为公安工作输 送具有高度法治思维、法律判断力, 具备良好网络技 术和网络管理能力的网络警察。

\section{4. 网络安全卓越警务人才培养计划构建}

\section{1. 卓越警务人才培养计划制定思路}

网络安全卓越警务人才计划制定要高站位“以服 务国家网络安全战略和更高水平平安中国建设” 需求 为牵引; 遵循新理念, 按照网络保卫工作和“新工科” 建设要求; 构建新方案, 明确网络安全保卫卓越人才 培养新标准、制定选拔创新方法与培养方案、形成多 样化、多渠道保障评价方式等。具体思路如图 1 所示。 


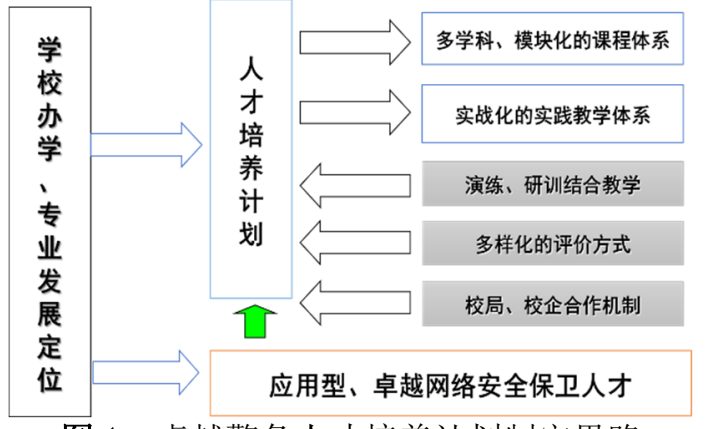

图 1 卓越警务人才培养计划制定思路

一所学校的办学定位、发展目标是专业发展的基 础。以警察大学为例, 警察大学具有良好的办学历史 与传统, 转制前作为一所公安现役院校所形成的使命 意识和责任意识已经内化学校的办学理想、价值追求、 精神品格和文化品质。转制为警察大学以来, 一直秉 承服务国家安全战略需求、承担国家责任的理想想念, 以有特色、高水平、国际化的世界一流警察大学为使 命而努力奋斗。这样的办学传承与基因决定了其在学 科、专业定位、发展上的特点, 转制以来, 先后开设 了网络安全与执法、数据警务技术等公安技术专业, 这些专业具有很强的时代特点, 数据警务技术是首次 申报并实现招生的新专业, 学校正在构建以智慧警务 模式下的学科、专业群, 这为卓越警务人才的培养提 供了平台支撑。

公安院校学科、专业具有很强的职业导向, 设计 专业人才培养计划既要考虑所在学校的办学特色, 也 要符合卓越人才成长的未来发展之路。网络安全卓越 警务人才就是要精准对标公安业务, 服务网络工作保 护工作, 这样的培养定位就决定了培养过程中要与公 安实践紧密结合, 不仅在课程设置, 也需要在培养方 式上注重实战。在此情况下, 一个问题就暴露出来, 就是公安教育属于高等教育体系, 必须遵循一定的高 等教育规律, 如何解决教学与实战的衔接? 在培养计 划制定中需考虑组建实战化的教学团队, 改进教学方 式, 实现 “教、学、演、战”一体化人才培养。需要 特别指出的就是演的环节, 构建基于实战案例的演练 环境, 在演练中实现知识、理论的转化, 在演练中培 养公安思维, 在演练中锻炼公安品性。

网络安全卓越人才计划制定要需要统筹规划, 注 重多学科的融合交叉。新智慧警务模式下, 强调合成 作战, 注重多警种的配合。公安情报、大数技术据、 网络安全等专业技术融合趋势明显, 网络安全须依托 数据、情报的支撑, 反过来亦然。因此, 网络安全卓 越人才培养计划在涵盖专业人才的选拔、专业课程体 系的重组、教学方法的创新、评价体系的构建等教学 的全流程、全要素过程中, 可以考虑以业务为牵引的 知识重组教学, 以案例教学带动多业务知识的融会贯 通。

\section{2. 网络安全卓越警务人才培养计划具体内 容}

人才培养依靠专业教学实现, 网络安全卓越警务 人才依托网络安全与执法专业。因此, 这里构建的网 络安全与执法卓越警务人才培养计划可以概括为, “围绕网络安全保卫卓越警务人才目标, 多方式选拔 优秀学生, 创新课程设置, 多渠道汇聚优质资源, 积 极创新教学模式, 建立多样化的保障、评价制度”， 如图 2 所示。

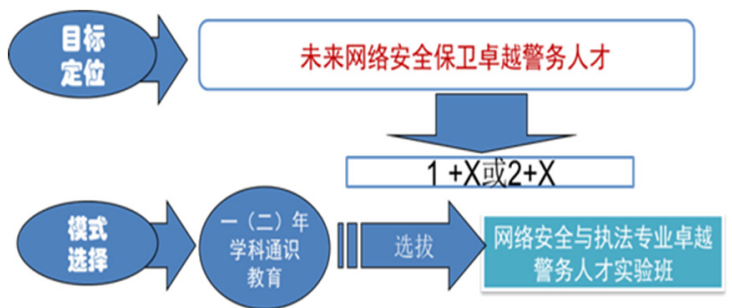

图 2 卓越警务人才培养计划制定思路

\section{2. 1. 网络安全卓越警务人才培养目标}

卓越人才培养目标与专业需求、公安特点相融合, 既明显高于现专业培养目标, 又充分体现公安工作实 战需求, 是一种专业上的精英教育。以网络安全与执 法专业为例, 专业培养具有法治意识和国际视野, 富 有实战经验与创新精神, 能够在公安机关网络安全保 卫部门从事网络安全保卫工作的高素质应用型警务 人才。而该专业卓越警务人才培养目标将在此基础上, 更加明确其在专业哪些方面卓越, 比如在网络犯罪侦 查方面, 则要求具有更敏锐的侦查思维和网络案件侦 破嗅觉, 更高要求的网络实战技术等。新工科理念下, 在卓越人才培养计划制定时, 要考虑跨学科、跨专业 的融合，可体现数据警务技术、网络安全技术和公安 情报等专业素质的综合要求。

\subsection{2. 多方式选拔优质生源}

网络安全人才的选拔要不拘一格, 在学校本专业 可以从每年秋季学期开始, 采用自主报名择优选拔的 方式, 每年从网络安全与执法专业大学一年级学生中 遴选 30 名学生组建网络安全卓越人才实验班。遴选 过程中尊重个人志愿, 做好日常评价的运用, 开展知 识性与实践性两方面的考察，适当时候开展面试答辩 的形式进行选拔。也从其他专业选择具有网络安全学 习兴趣、发展志向的学生加入, 注重学科间的交叉。 对于具有特殊才能或发展前途的学生可以给予特殊 录取。

\subsection{3. 创新课程设置体系}

课程是人才培养的支撑，在课程体系中，按照公 安实战要求, 增加课程中实践课时, 增加实战内容, 特别是核心课程中增加案例教学; 课程可跨学科设置, 可根据法治、技术、管理等知识的融合开设新课程。 
选修课程采取线上和线下相结合的选修模式, 学生 可选修指定列表的网络课程，考核通过后，获取选 修学分 ${ }^{[5]}$ 。网络安全与执法专业卓越人才培养突出网 络对抗演练/实战技术、网络安全分析等网络安全与 执法专业核心能力，可引入工程教育认证体系。

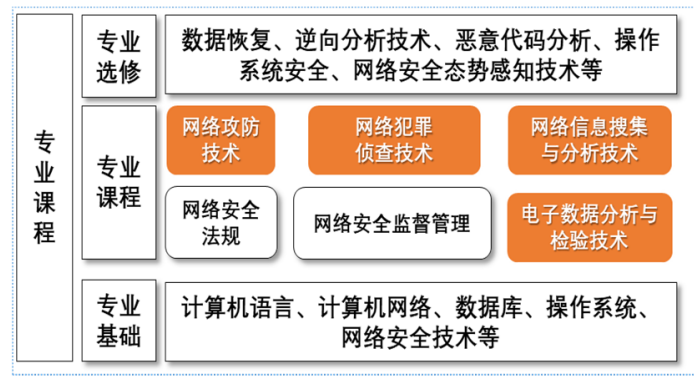

图 3 卓越警务人才课程体系

\section{2. 4. 积极创新教学模式}

采用小班上课模式和多样化的课程考核方式, 突 出网络安全攻防技术与实战, 采用的以问题为导向的 教学方法和基于团队的教学模式, 培养学生的自主探 索能力, 针对“网络攻防技术”、“网络犯罪侦查技术”、 “网络信息搜集与分析技术” 等工程实践性较强的 课程, 实践临床医学中采用的以问题为导向的教学方 法和基于团队的教学模式, 以一些开放性的实际问题 为学习起点, 培养学生的自主探索能力。

鼓励、激励学生参加各类网络安全学科竞赛。毕 业实习阶段将学生安排到网络安全保卫重点部门、网 络安全企业进行实践锻炼, 逐步形成 “实战引领、校 局、校企合作、政产学研协同育人” 的人才培养模式。 教学过程中, 讲座、案例等多种形式开展新技术、新 犯罪的讲解, 注重实战专家的引进, 实现教师与一线 干警共同教学, 形成合力。

\subsection{5. 多渠道汇集优质资源}

依托网络安全创新实验平台, 汇集全校、公安网 安部门及知名网络安全机构、企业等人力资源, 组建 网络安全理论与法治、网络攻防技术、网络犯罪侦查 技术、网络安全态势感知等专业教学团队, 人员组成 上注重学缘结构多元化, 能够实现 “学术导师和实践 技能导师的双师制” 的教学, 可结合专业特点构建专 家、一线民警库; 建设网络安全保卫卓越人才创新平 台, 引入公安实战平台, 可以发挥虚拟现实等信息技 术的优势, 利用 VR 技术建设基于公安实战案例的网 络安全执法虚拟仿真实验资源, 学生在学校通过这些 资源就可练习，提升专业实战思维和能力。

\subsection{6. 制定多样化的的保障、考核评价方式}

卓越警务人才的评价不能简单以分数或学分等 结果考核方式, 不拘一格选人才更应不拘一格评价人 才, 其培养计划应注重质量评价由内部评价、自我评
价、结果评价向过程评价、社会评价、学生评价、单 位评价转变。在计划制定中, 允许学生通过 “以证代 课、以赛代课” 的方式申请课程免修。要注重奖励、 激励机制在卓越人才培养中的作用, 在学生奖励评选 中, 由于单独组班并且都是优秀学生, 因此, 在奖学 金评定、推优推先等方面予以政策倾斜。

\section{5. 结论}

在新工科、卓越计划 2.0 理念指导下，公安教育 围绕智慧新警务对公安卓越警务人才的需求, 落实好 全国高等教育工作会议精神，立足各自院校办学特点、 学科、专业特色, 为培养 “兼备德法技能” 的网络安 全卓越警务人才, 要不拘一格选好生源, 构建科学、 开放的人才培养体系, 形成以实战为导向的卓越警务 人才培养计划, 优化课程体系, 创新教学方法, 加强 教学资源建设特别是虚拟仿真实验教学, 面向实战, 强化理论储备与技能锻炼, 注重实战技能的训练。多 措并举, 多方合作必能开创公安院校卓越警务人才培 养新格局。

\section{项目基金}

本文为河北省教育教学改革与实践项目于《网络 安全与执法专业卓越警务人才培养计划研究》、警察 大学《网络空间安全学科多元化创新人才培养实践体 系构建研究》的阶段性成果之一。

\section{References}

[1] Gu P.(2017)The Concept, Framework and Implement Approaches of Emerging Engineering Education (3E) and the New Paradigm, Research in Higher Education of Engineering,6:1-13.

[2] ZENG Y., WANG Q. Building First-class Undergraduate Education with High Standard According to "40 Articles of Higher Education in the New Era",Research and Practice on Higher Education, 2:1-10.

[3] WANG Ch., CHEN J. (2021) Research on the Training Path of Outstanding Police Talents under the Background of Building a Country Ruled by Law, Journal of the armed police academy, 37(01): 77-84.

[4] Ma J., Tian J., Zhang Y. (2021) Research on the Training of Innovative Applied Talents in the Field of Cyberspace Security and Law Enforcement under the Background of New Engineering, 37(02),78-82.

[5] Ma J., Tian J., Zhang Y. (2020) Science and Engineering Research Center. Proceedings of 2020 International Conference on Education E-learning and Social Science(EELSS 2020)[C].Science and Engineering Research Center: Science and Engineering Research Center.5. 101-105. 